\title{
Digital Media versus Human Communicativity: the Emotional and Family Communication Dimension
}

\author{
Beryl Annette Ehondor \\ School of Media \& Communication, Pan-Atlantic University, Lagos, Nigeria \\ *Email: beryl.ehondor@pau.edu.ng
}

\begin{abstract}
The media's permeation into the human ecosystem has adjusted the hitherto traditional relationship with digital spatiality, time, culture and human communication. This paper identified the interconnectivity between the concepts of digital spatiality, time, culture, human communication and divorce rate by critically appraising their impact with a focus on the family, being the microcosm of society. Through Emotional Intelligence Theory, this paper indicated emotional connections as the object and subject of digital spatiality, time, culture, and human communication. This is relevant at this period that the media has permeated our social system and ecology. This paper deployed textual and conceptual content analyses to unearth finding on the topic. Findings showed that technology grows exponentially through time and cultures, easing communication. However, divorce rates are also exponentially higher through time and cultures despite the ease in communication via technological innovations. Therefore, this study is significant at this time of new media challenges in family communication. Also, in the aspects of self-disclosure and applying emotional intelligence for human communicativity online and trans-culturally. Further research and integration of emotional intelligence in communication innovations in homes, relationships, and the entire human existence should be further explored based on the findings.
\end{abstract}

Keywords: Family-Communication, New media, Emotional Intelligence, Self-Disclosure, HumanCommunication

DOI: $10.7176 / \mathrm{NMMC} / 96-06$

Publication date:May $31^{\text {st }} 2021$

\section{Introduction}

"Our devices matter to us as much as food and shelter. Technology has altered the flow of time. The overall time that we have for our narrative, our life span, has been increasing, but the smallest measure, the moment has shrunk" (Dawaesar, 2013). The world has experienced several eras of digital evolution. These eras account for what is known as 'Digital Spatiality', and it refers to eras and time-spans of digital evolution in the world. Evolution is spoken of concerning time, and time is an underlying factor for digital evolution. Over the past century, things have changed concerning how human communication affect our modes. Culture is also seen to have evolved and metamorphosed very gradually and has allowed for newer inclusions and reforms. All of these subtle changes affect the lifestyle of people. Culture is the way of life of people in a particular society (Griswold, 2012). Going by this definition, it is clear why the family, which is the basic unit of society, is affected positively and negatively by digital evolution. Centuries ago, when there were no mobile devices and very few computers, human communication was primitive and intentional. There were usually no such things as a phone ringing or message notifications, so such distractions were non-existent. However, communication was very tedious.

For as long as humans have existed, communication has been evident. Despite the myriad of languages that exist and have existed, humans still communicate one way or another. In the early days, before the middle of the $20^{\text {th }}$ century, human communication was very crude. The $19^{\text {th }}$ century predominantly featured newspapers, signal lamps at critical spots, not-to-mention. The electric telegraph made it possible to transmit information farther and to more people at once than ever before. Then came the Telegraphs, and by the $19^{\text {th }}$ Century, Television changed the landscape of communication forever when it was first introduced in 1927. (Holtzapple, 2015) Communication had followed a notable trend from a time of storytelling, when people gathered around elders to hear stories about their origin, to a time where writing became a way of life. Documents were written with ink and feathers. The books were written by hand. Hence, the word 'Manuscript' originated from the Latin term "Libri manuscript" and translated to "Book written by hand". Hence, this new invention caused humans to learn to read, altering the usual lifestyle of just listening and speaking. 
There were not many manuscripts available to be read, so humans still had to come together to listen to someone read the writings, especially in religious settings. However, in 1448, the Printing Press was initiated by a German man named Johann Gutenberg. This development fostered reading and writing culture. The need now arose to get these writings across to families and friends who were not physically present. This birthed the process of letter writing and posting, and in no time, it became a way of life, and people could send their loved ones notes notwithstanding their physical distance.

Having followed the process through, letter writing and posting as a human communication method soon showed its flaws as the letters either reached their recipients long after they were sent or were misplaced in transit. As a result of these occurrences, an Englishman named William Watson devised a way to send messages via something he termed 'telegraph' in 1747. The telegraph sent messages electronically through wires, which meant that communication was faster and more efficient. After the telegraph, the telephone was introduced, followed by radio, the television and then the Internet, where everything is everywhere at the same time.

It is important to note that these improvements experienced in communication over time were due to perceived gaps and an overall desire to improve human communication. Therefore, it is pertinent to note that one major factor that drives digital evolution is man's increased desire to communicate more effectively. The pressing desire to move one step further has led man to create a new means of approaching a challenge. This implies that since our needs are insatiable, the chances are that newer developments will be made continually at even shorter intervals. Time here is the factor that will also determine what changes are evident. Following the development trend, it will not come as a surprise if the Internet is overshadowed by something even more robust and efficient in no time. This also begs whether digitisation has made communications more effective within its evolution and represents the 'utopia' of human communication. Digital spatiality, time, culture and human communication remain interdependent, and the family is the root recipient of its effects, whether pleasurable or detrimental.

Several factors hinder effective human communication in our digital era across cultures and families, like language, culture, time-span, age, gender, literacy, personality, religion, channel, social media misuse, ethics, etc. This paper will focus on the emotional dimension and issues in human and family communications despite digital evolutions purposed for effective communication.

\section{Methodology}

This qualitative research engaged textual and discourse analysis. The methodologies involved understanding language, symbols, and/or pictures present in texts to gain information regarding how people make sense of and communicate life and life experiences in digital media culture. Visual, written, or spoken messages provided cues to ways through which communication was analyzed for this social context.

\section{Theoretical Framework Emotional Intelligence Theory}

Emotional intelligence (E.I.), according to Gayathri \& Meenakshi (2013), is the eighth added to the theory of multiple intelligences, which holds that every human person has bits of intelligence and exhibit varied combinations of this intelligence. Emotional intelligence is a measure of how good people are at interpreting, understanding and acting on emotions and the emotions of others. Mayer \& Salovey (1997) propounded the Emotional Intelligence Theory and succinctly described E.I. as the ability to recognise emotions, to receive and initiate emotions to assist thought, to understand emotions and emotional knowledge, and to regulate emotions to promote emotional and intellectual growth reflectively". It is an understanding of the root causes of emotions, their use in effectively identifying SELF and appraising interaction with other human persons. It also encompasses five components, i.e. self-management, self-awareness, self-regulation, internal motivation, empathy and social skills (Goleman, 1995). Summarily, however, Emotions combine the qualities of rationalising and feelings in human communication. 


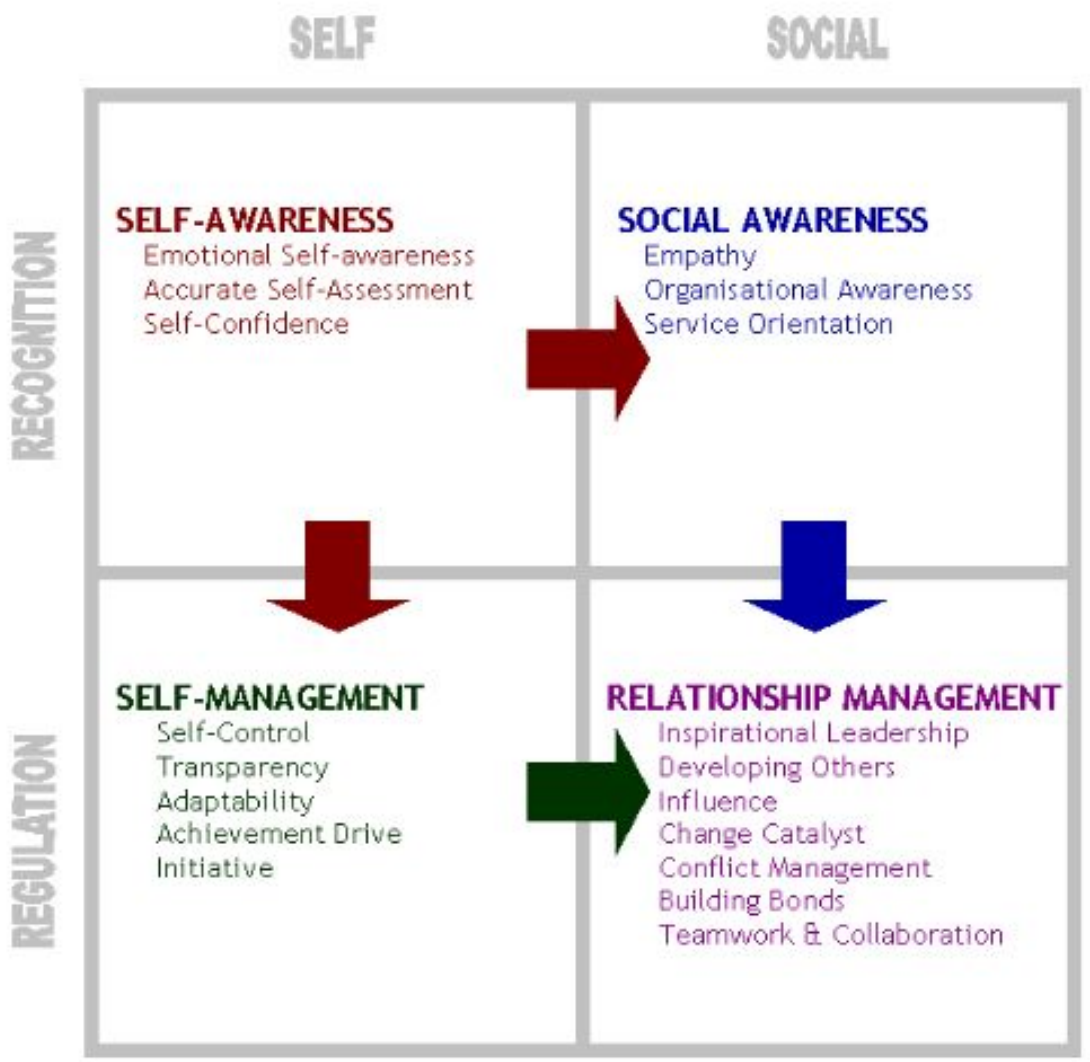

While some researchers view emotional intelligence as purely a cognitive ability, others consider it a personality trait (Gayathri \& Meenakshi, 2013). Humans are rational beings with cognition, however cognitive intelligence and abilities are not enough. Mere cognitive abilities without emotional intelligence are dangerous in human relationships and to society.

Hence the need to adapt emotional intelligence in all forms of human communication, especially in digital spatiality, culture and time. If individuals are self-aware, internally motivated, empathetic, have self-control and proficient in social skills, including leadership. The propensity to tilt towards the earlier identified hindrances and opposing sides of digital communication technology will drastically be obliterated. Even as communication technologies tilt to face-to-face and biometric identities, this paper recommends further research into integrating emotional intelligence components [self-management, self-awareness, self-regulation, internal motivation, empathy and social skills] in developing communication technology.

\section{Self Disclosure}

The self-disclosure concept is the act of deliberately revealing details about ourselves to another person or people - the issues in disclosure spans from releasing 'unimportant' details to sensitive and then personal information. Self-disclosure evokes trust and develops human relationships. It is also necessary for uncertainty management. Self-disclosure can be verbal or non-verbal [even though this paper is focused on non-verbal] and features vulnerability and reciprocity as outcomes of the disclosure. Philosophies that emphasises self-disclosure while explaining human communicativity and relationships include Johari window of self, Social Penetration Theory (SPT), communication privacy theory (CPT), and Social Exchange Theory (SET) (Masaviru, 2016) . Disclosure is a critical factor in the development and sustenance of human communication. Self-disclosure enables the permeation of boundaries, benefits of interactivity are well-thought-out, and information flows freely. Intimacy grows as disclosers' peel off' the 'artificial barriers' to the core persona while connecting as social beings. 
Individuals amidst families must embrace 100 per cent self-disclosure through every communication channel possible to make their relationship stronger regardless of where technology takes us in the future. In connecting with persons outside the immediate (nuclear) family, prudence must be employed in determining what to disclose or otherwise.

\section{Conceptual Framework \& Discourse Analysis} The Connecting Link between Culture and Human Communication

Human communication is social and cognitive because it is a process by which individuals exchange information and influence one another through a common system of symbols and signs. (Higginsa \& Seminb, 2001). Communication is primarily connected to culture as it defines how humans are to express themselves over time. Within the confines of culture, there exist certain factors that affect communication between humans. Like anatomy, human communication and language skills develop throughout time. (M. \& M.S., 2017). Not only do they develop, but they are also improved upon over a certain period. Kroeber \& Kluckhohn (1952) has emphasised that:

Culture consists of patterns, explicit and implicit, and behaviour acquired and transmitted by symbols, constituting human groups' distinctive achievements. These include an embodiment in artefacts as the essential core of culture consists of traditional (i.e. historically derived ) ideas and especially their attached values; culture systems may, on the one hand, be considered as products of action, on the other, as conditional elements of future action(p.)

Today, most social scientists view culture as consisting primarily of the symbolic, ideational, and intangible aspects of human societies. The essence of a culture is not its artefacts, tools, or other tangible cultural elements but how the members of the group interpret, use, and perceive them. It is the values, symbols, interpretations, and perspectives that distinguish one people from another in modernised societies; it is not material objects and other tangible aspects of human societies. People within a culture usually interpret the meaning of symbols, artefacts, and behaviours in the same or similar ways. (Banks \& McGee, 1989)

Communication is a fundamental factor of the humanisation process. However, an upgraded and refined culture propagates a holistic form of communication. Culture creates the platform for interoperability. Communication is an intrinsic part of man's existence, whether it is verbal or non-verbal. The interdependence between culture and communication shows why one expression is accepted in one community and yet perceived as obscene in another community. Thus, to a considerable extent, culture creates the benchmarks through which communication comes to life.

Culturally, in many parts of Europe and America, shaking hands is accepted as a salutation form. However, in Thailand, shaking hands is disrespectful and unapproved. Also, in Russia, people of the opposite sex are only permitted to shake hands during business meetings. Another instance is the culture of greeting with a kiss. While this gesture is typical in France and Italy, it is disrespectful and, in fact, totally unheard in some parts of Africa. This situation shows that people's culture is directly mapped to how they communicate their thoughts and feelings. The never-ending nature-nurture arguments and research show evidence indicating both can influence traits and even diseases in persons. However, it is worth noting that the ratio is 50:50 between genetic and environmental differences (Aust., 2003). Benyamin's (n.d.) study also shows that our social values, for example, are $70 \%$ environmental and $30 \%$ genetic. Culture and human communication are tightly linked, and every digital evolution or regression has a significant impact on the family, which is the basic unit of society. One of the salient [consistently recurrent] features of human communication that cuts across culture, digital spatiality, and time is emotions, hence the need to delve into human communication's emotional aspects.

\section{Emotional Aspects of Human Communications}

As human persons within society, we are nurtured utilising socialisation to understand, interpret and express feelings. Emotions are physical, characteristic, social interactivity and expressed responses to spurs rationally handled as emotional (Sally, Julie, \& Beverley, 2006). Human culture affects how persons express their emotions, and hence, affects human communication.

In describing the human psyche, the essence of life, Aristotle mentioned emotions as core to existence. Emotions are real, and they exist to help humans communicate appropriately, sending the right signals even without necessarily speaking. Arguably, there are no good or bad emotions. Instead, they are indicators that help humans explain how or what they feel. Caruso (2008) explains that emotions channel our attention, motivate engagement 
in some behaviours, are fundamental for every effective decision making and will not interfere with proper decision making.

\section{Types of Emotions}

Primary emotions are innate emotions that are experienced for short periods of time and appear rapidly, usually as a reaction to an outside stimulus, and are experienced similarly across cultures.

The primary emotions are joy, distress, anger, fear, surprise, and disgust. Members of a remote tribe in New Guinea, who had never been exposed to Westerners, were able to identify these basic emotions when shown photographs of US Americans making corresponding facial expressions. (Evans, 2001). All around the world, the smile of a baby asleep or awake would normally evoke a smile and is interpreted as beautiful. It is often said that a smile has no tribe.

Secondary emotions are not as distinctive as primary emotions, and they do not have a corresponding facial expression that makes them easily identified. Secondary emotions are processed by a different part of the brain that requires higher order thinking; therefore, they are not reflexive. Secondary emotions are love, guilt, shame, embarrassment, pride, envy, and jealousy (Evans, 2001).

These emotions are built over time and they take longer to disappear. They are usually interpersonal because they are most often experienced in relation to real or imagined others. The same way a person is ashamed of something he said or did, or embarrassed becaupe of the incompetency he displayed on a stage. Although there is more cultural variation in the meaning and expression of secondary emotions, they are still universal in that they are experienced by all cultures.

Emotions are a critical part of emotional intelligence. They are the eight added to the theory of multiple intelligences, which holds that every human person has intelligence and exhibit varied Combinations of these bits of intelligence (Gayathri \& Meenakshi, 2013). While some researchers view emotional intelligence as purely a cognitive ability, others consider it a personality trait (Gayathri \& Meenakshi, 2013). It is an understanding of the root causes of emotions, their use in effectively identifying SELF and appraising interaction with other human persons. It also encompasses self-management, awareness, regulation, motivation, empathy(Goleman, 1995). Summarily, however, emotions combine the qualities of rationalising and feelings in human communication.

\section{Human Communication in Time and Culture}

Human beings coming together in clusters and fostering interpersonal bonds are fundamental to survival species, the capability to express emotion made this possible (Sally, Julie, \& Fehr, 2006). The human relationship is becoming increasingly complex, and the ability to manage conflict, control our anger and generally show empathy increases our capacity to deal with living with more people.

Couples living together have to understand their sentiment intricacies to cultivate the union. Emotions are first felt, but how they are expressed determines how the receiver consumes them and reacts to them. There are also specific cultural models regarding which types of emotions can be expressed. In individualistic cultures, especially in the United States, there is a cultural expectation that people will exhibit positive emotions. Recent research has documented the culture of cheerfulness in the United States (Kotchemidova, 2010). People seek out happy situations and communicate positive emotions even when they do not necessarily feel positive emotions. Being positive implicitly communicates the achievement of personal goals, to have a comfortable life, and to have a healthy inner self (Mesquita \& Albert, 2007).In contrast, however, the people who live on the Pacific islands of Ifaluk do not encourage happiness because they believe it will lead people to neglect their duties 
(Mesquita \& Albert, 2007). Also, collectivistic cultures may not appreciate one's expression of positive emotion because it implies that the person is bringing undue attention to themselves, which could upset group harmony and potentially instigate jealous reactions from others. However, in a positive culture, failure to express positive emotions could lead others to view a dismal person and require psychological therapy.

It is interesting to note that emotional expressions of grief also vary among cultures and are often tied to religious or social expectations (Lobar, Youngblut, \& D., 2006). Thai and Filipino funeral services often include wailing, a more intense and loud form of crying, which shows respect for the deceased. The wailing's intensity varies based on the importance of the individual who died and the closeness of the relationship between the mourner and the deceased. Therefore, close relatives like spouses, children, or parents would be expected to wail louder than distant relatives or friends. In Filipino culture, wailers may even be hired by the family to symbolise the importance of the person who died. In some Latino cultures, influenced by the concept of machismo or manliness, men are not expected or allowed to cry. Even in the United States, there are gendered expectations regarding grieving behaviours that lead some men to withhold emotional displays such as crying, even at funerals. All these show that the expression of emotions as a form of human communication is regular, dynamic, a fundamental experience but broadly varies across cultures even in similar climes, not to mention diffusion resulting from migration and globalisation.

\section{Non-Verbal Communication and Human Interaction in a Digitized World}

The recurrent thread in digital spatiality, time, culture and human communication is the essence of communicability, to connect as social beings, feeding our emotional needs. This condition underscores the need to focus on the emotional aspects of communication, which is non-verbal communication. Attention to nonverbal communication is critical in a digitised world, significantly because it has evolved into a global village. Innovations in communicative technology, e.g. social media applications and devices, are made almost immediately available worldwide because of the Internet's ubiquitous nature. Hence the need to consider one of the adapted modes of communication across geographies, non-verbal.

The primary objective of all communication technology across time is to communicate. Good communication is the foundation of any successful relationship, be it personal or professional. Non-verbal communication, or manual language, uses signals to propagate messages, send and receive messages without spoken or written words. In today's digitised cummunicativity, features that fall under non-verbal communication encompass the use of emojis, avatars, gifs, memes, type of font, colours, sound, graphical expressions actively used by networking sites, software, platforms and applications. The futuristic organisation's current drive is an investment in UI/UX (user interface /user experience design) and expressive designs that employ much psychology to sustain attention.

Judee Burgoon (1994), in the course of research on the Interpersonal Deception Theory, identified seven different non-verbal dimensions:

1. kinesics or body movements including facial expressions and eye contact;

2. Vocalists or paralanguage that includes volume, rate, pitch, and timbre;

3. Personal appearance;

4. Physical environment and the artefacts or objects that compose it;

5. Proxemics or personal space;

6. Haptics or touch; and

7. Chronemics or time. (To this list, we would add signs or emblems)

They may vary from the monosyllabic gesture of a hitchhiker's prominent thumb to such complex systems as the American Sign Language for the deaf, where nonverbal signals have a direct verbal translation. However, it should be emphasised that signs and emblems are culture-specific. The thumb and forefinger gesture used to represent 'A-Okay' in the United States assumes a derogatory and offensive interpretation in some Latin American countries."

(Schmidt et al., 2007). Here in Nigeria, some non-verbal cues include a mother's look, usually laden with broad and circumstantial meanings to the child. Gesticulations to elders adjudged rude or respectful, which varies across different tribes. 
- Repetition: they can repeat the message the person is making verbally.

- Contradiction: they can contradict a message the individual is trying to convey.

- Substitution: they can substitute for a verbal message. For example, a person's eyes can often convey a far more vivid message than words.

- Complementing: they may add to or complement a verbal message. A boss who pats a person on the back in addition to giving praise can increase the impact of the message.

- Accenting: they may accent or underline a verbal message. Pounding the table, for example, can underline a message.

Source: The Importance of Effective Communication, Echard G. Wertheim, Ph.D.

\section{Non-verbal communication cues can play five roles: according to Wertheim}

Two 1976 studies compared vocal cues with facial cues. While other studies have not supported the 93 per cent, it is agreed that both children and adults rely more on nonverbal cues than on verbal cues in interpreting the messages of others (Roy M, 2007).

Many platforms now allow avatars to be computer-generated graphical and somewhat animated images representing users and set on profiles during interactions. There is usually a range of options to choose from, whatever is preferred, from human caricatures to animals, objects etc. (Allmendinger, 2010). People, however, tend to connect more when the avatar looks more like the human person behind the online conversation (Baylor, 2011).

Human persons have gradually acclimatised with patterns of cummunicativity initially very alien [there are usually laggers and early adopters]. It is interesting to see how quickly we flow with it as though we have had it all our lives. Our communication continuously evolves, all thanks to digital spatiality. However, the impact of our largely digitised communication must be appraised, lest we are eroded of our essence as social beings.

\section{The Impact of Contemporary Digital Spatiality on Human Communication}

With the plethora of social media websites and automation services available to us and accessible through a single pocket device, the way we interact with each other has completely changed. These social media platforms - Facebook, LinkedIn, Twitter, Instagram, and Snapchat, achieve one primary goal in particular. The main purpose is to enable communication and sharing of experiences across borders without the 'flaws' of geographical differences. Social media brings people together, whether families, friends, colleagues or new acquaintances. To meet humans' needs, software applications have increased in complexity in terms of capabilities and decreasing complexity. This means that though the engineering procedures are getting more complex, these processes have permeated humans' way of life so much that they use it effortlessly.

The most popular communication gadget in this era would be the mobile phone. After television and laptop/desktop computers, as reiterated by Rao \& Mendonza (2005), the mobile device appears to be the $3^{\text {rd }}$ main screen in people's lives, primarily because of its convergence capabilities. It combines format [text, sound, image, file size] and optimises the Internet's ubiquity. Today, Apple is worth over one trillion dollars; this indicates mobile telecommunications' success worldwide. This trend indicates future innovations, a knowledge economy without bounds and Flexi organisations, like are already budding. Human communicativity evolved from cave scribblings to orality and written communication within time, building on sophistication with each era and then unto digital technology, which deemphasises word and thrives on visuals. This era in digitised communication facilitates the capture, saving, and cataloguing of persons' memories and events, as each life is a story, one that's connected to everyone else's. Thus selfies adorn timelines, status updates and storyboards, with the users attempting to gain some attention, perhaps respect, regardless of their true personalities. So we see here that digital spatiality in human communication across cultures has its pros and cons, both making and marring relationships depending on how these applications cum devices are utilised. 


\section{The Positive Impact}

As mentioned earlier, today's era in digitised communication facilitates the capture, saving and cataloguing of memories and events of persons; each life is a story, one that's connected to everyone else. This situation is evident in the selfies, timelines, status updates and storyboards etc. We just attempt to connect with other humans.

Generations to come will have an extensive repository of information to fall back to when addressing matters about history. Facebook does this so well with 'friend-adversaries, bringing back memorable events, pictures or conversations shared online years before, cataloguing the past and enabling reminiscing the moments to rekindle relationships.

Peer support through newsgroups was one of the first Internet developments that participants have found helpful [though much self-help is involved]. This reflects in the number of participants, referrals and engagement within the fora. These groups are focus-grouped and devoted to a wide range of family and life issues like Ask the Gynecologist, Females In Nigeria (FIN). (King \& Moreggi, 1998). There are a lot of online support bodies that support persons with disabilities or terminal diseases. These groups encourage persons in this category, thereby ripping stigmatisation and extending arms of love.

Survey results have also shown that more persons are confident and expressive about their feelings with communication technology. Most chat platforms have loved ones expressing their feelings by texting it and not necessarily saying it openly. The digital revolution has reduced such tension. Digital spatiality and evolution have given rise to a storeroom of information, so much that humans cannot take them all in. Google, Bing and the rest are search engines that make it possible to search for anything that comes to mind. Also, with Youtube, humans can watch videos of any sort, including videos that say how to do a particular thing. Communication via technology has helped people find love and sweethearts via dating sites, sometimes culminating in marriages. The survey by the dating experts, eHarmony A.U., reveal 1 in 10 people who visit dating sites found love via the Internet. Applications like Skype, Facebook and WhatsApp video calls enables friends and spouses to experience the next best alternative to each other's company. More immediate than mail via the post office, cheaper than international phone calls, communication technology is an invaluable asset for bonding and sustaining relationships regardless of geography.

\section{The Negative Impact}

Having mentioned some of the significant impacts of digital evolution on culture and human communication, it is also expedient to mention the ills that come with it, especially about families. The way of life of people has been altered with the advent of these devices. Families have organised their activities to accommodate cell phones and laptops. This has, in turn, reduced the average time available for personal conversations. Some reports have it that couples communicate through their phones even while in the same building, while others are on their gadgets with the rest of the children while in the living room. Britons spend more time on tech than on sleep (Ofcom, 2016). They also spend an increased amount of time online and with gadgets than face-to-face with friends and family. This has led to a significant reduction in intimate family connections and interactions. For instance, my father leaves home at $5.30 \mathrm{am}$ and is already on the phone checking emails and assigning tasks to sub-ordinates while in traffic. He is engaged with his phone and laptop while working until past 7 pm. Travel time back home sometimes exceeds 2hours, during which the mobile phone is engaged half the duration, touching base with clients, colleagues and family. Overall, the communication touchpoints with immediate family [including calls] amount to less than 2 hours between sleep times. While he is out to fend for the family, intimacy is threatened despite available communication technology. "Cell phones seem to prioritise communication with distant people over those sharing one's space, and the ethics of this new behaviour are not universally agreed upon”.

In many instances, the older citizens are dependent on the young generation for their technical know-how to understand the functions of a smartphone and any other gadget based on digital technology, being early adopters. This catch-up process puts the older person in a submissive position in a bid to learn. Their slow pace in catching up combined with adolescents' characteristic impatience sometimes leads to aggression from the younger. It is also observed that in the family's day-to-day affairs, the younger generation's opinions surpass the elders' opinions online. The young generation being skilled and having a more significant number online are given older folks' preference digitised communicatively, especially as laggers in technology. Adolescents and many young people sometimes fiddle with their smartphone while interacting with parents and older family members. To the adult at the receiving end, this indicates being undermined. Regarding the increasing ownership and use of 
smartphones, there are arguments that the line between gender distinction and the generation gap of human persons is thin. Based on stats from the Ministry of communication and information technology in Saudi Arabia (2014), a culturally high context nation, Aruba and America, the numbers of children, rising above 33 million, hooked on gaming is alarming;

- America $88 \%$

- Arab world $80 \%$

- Aruba $80 \%$

In some cases, the addiction to Video game started as an escape from the 'real world' and became a psychological problem when the player loses touch with the real world, sometimes leading to their harm. This is a severe problem and should not be tolerated by the parents. This addiction to games is even evident during family \& meal times.

To connect with other human persons, individuals in the family are seemingly more connected to friends online than family. In 'connecting' to other human persons, they disclose personal information, inadvertently enabling online bullying, phishing, identity theft, spamming, and other related cybercrimes to thrive.

Recently a family friend was advised to take down a particular picture and information from Facebook. His pretty 3-year old daughter was dressed up in Igbo traditional wear for a cultural day at school in the post. He shared her picture for friends to admire and 'like', mentioning her school's name. That post [judging from gory tales online in the recent past] was enough information to ease the kidnap of that child for extortion, rape or something sinister. This underscores the point of discretion in self-disclosure and applying emotional intelligence for human communicativity in online communications.

\section{Impact of Digital Evolution on Marriages and Relationships}

On August $2^{\text {nd }}, 2018$, the world woke up to Apple (alone), now worth $\$ 1$ trillion, more than many countries put together. So while technological growth and adaptations are exponential growing vertically, the family connections are dwindling. Divorce rates have increased globally in frequency and are almost trendy. Statistics on global divorce rates on Amicable (2017), a U.K. national divorce service agency, indicate that the global divorce rate is rising. First marriages today stand a 45 percent chance of breaking up, and second marriages a 60 percent chance. This is in sharp contrast with the growth in digital spatiality. See table and charts below:

\begin{tabular}{|l|l|l|}
\hline S.N. & $\mathbf{1 0}$ Highest & $\mathbf{1 0}$ Least \\
\hline $\mathbf{1}$ & Luxembourg $87 \%$ & India $1 \%$ \\
\hline $\mathbf{2}$ & Spain $65 \%$ & Chile $3 \%$ \\
\hline $\mathbf{3}$ & France $55 \%$ & Columbia $9 \%$ \\
\hline $\mathbf{4}$ & Russia $51 \%$ & Mexico $15 \%$ \\
\hline $\mathbf{5}$ & Unites States $46 \%$ & Kenya $15 \%$ \\
\hline $\mathbf{6}$ & Germany $44 \%$ & South Africa $17 \%$ \\
\hline $\mathbf{7}$ & United Kingdom $42 \%$ & Egypt $17 \%$ \\
\hline $\mathbf{8}$ & New Zealand $42 \%$ & Brazil $21 \%$ \\
\hline $\mathbf{9}$ & Australia $38 \%$ & Turkey $22 \%$ \\
\hline $\mathbf{1 0}$ & Canada $38 \%$ & Iran $22 \%$ \\
\hline
\end{tabular}

Amicable (2018): Divorce rate by country as at 2017

Top reasons for these divorces include infidelity, incompatibility, drug abuse, physical abuse, with the reason of incompatibility or growing apart ranking highest at $44 \%$. This situation points to a breakdown in communication, as these were once inseparable. Technology was made to ease communication, so why are relationships falling apart? Emotional disconnection.

Figure 1,1 Show the reference below and recent findings. The study found a link between social media use and decreased marriage quality in every model analysed. It also found that a $20 \%$ annual increase in Facebook enrollment was associated with a $2.18 \%$ to $4.32 \%$ increase in divorce rates. The study's model from the individual survey results predicts that people who do not use social media are $11 \%$ happier in their marriages than people who regularly use social media. 


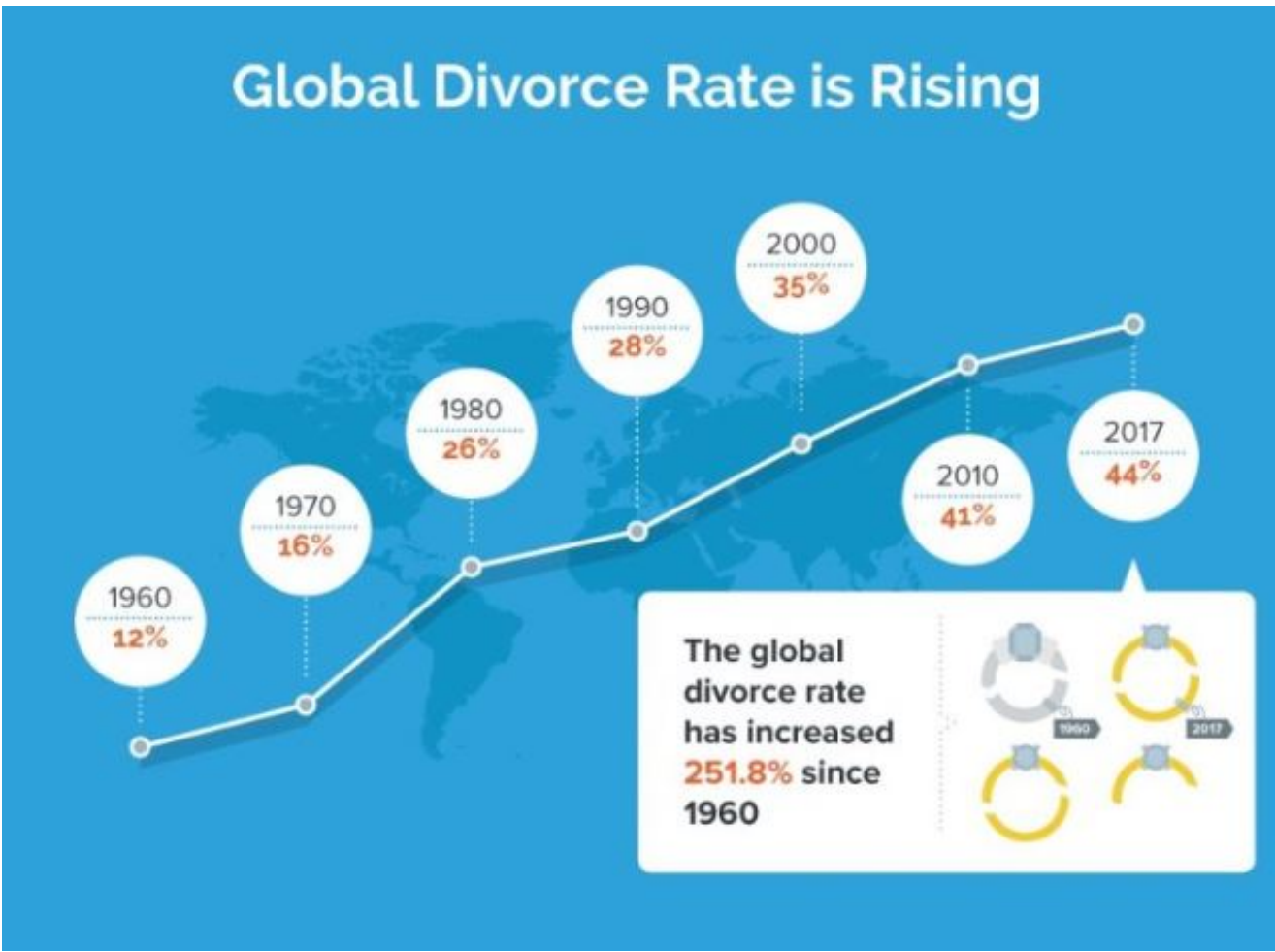

In some families, the challenge is Internet addiction, and the folks with addicts in their homes usually experience feelings of isolation or abandonment. Addiction involves the obsessive use of social media and other Internet outlets, disengaging from the surroundings, and withdrawing from family activities or conversations. (Livestrong, 2013)Many relationships are threatened by an online relationship engaged in by one spouse. Thus, intimate online relationships, even if not physical, may become familiar sources of tension in existing face-to-face romantic relationships because they are emotionally disconnected (Young, Griffin-Shelley, Cooper, O’Mara, \& Buchanan, 2000).

Over time, technology has presented tremendous opportunities for people in their love lives via dating sites and platforms to meet, while email, text messages, Skype, and other high-tech communication forms allow couples to interact across geographies. Social Media sites like Facebook have allowed friends and family to connect and reconnect with minimal effort. Unfortunately, this technology also frequently plays a crucial role in separation, divorce and other related issues. Just like any form of communication, technology and the Internet have the potential for spousal misuse.

Valenzuela, Halpern, \& Katz (2014) compared state-by-state divorce rates to per-capita Facebook accounts and had the following findings;

1. There is a relationship between social media use and decreased marriage quality in every model analysed.

2. $20 \%$ annual increase in Facebook enrollment coincided with a jump in divorce rates from $2.18 \%$ to $4.32 \%$

3. Couples off social media are $11 \%$ happier in their marriages than those active on social media.

4. The greater penetration of social media from 2008 to 2010 was positively correlated with increases in divorce rates.

Social media provides easy access for a suspicious spouse to snoop on online conversations with their partner. Whether suspicions are founded or not, people feel uneasy when they discover something on their partner's Facebook account. (Irvin, 2018) has noted that with the development of the Internet, the definition of infidelity now includes a romantic and sexual relationship with someone other than the spouse, which begins with an online contact and is maintained mainly through electronic conversations that occur through email and chat. Widespread use of the Internet has gradually led to a rise in online infidelity. Pre-existing marital problems include poor communication, sexual dissatisfaction, or boredom with the relationship. (Aust, 2003). Online 
infidelity has also been identified by researchers in this field as potentially devastating to the primary relationship and caution that it may become a significant factor in deteriorating marital relations. (Aust., 2003).

The above begs why relationships are suffering while technology breaks grounds to make communication 'easier' and individuals must do a relations-audit moving.

\section{Conclusion and Recommendation}

The wave of digital spatiality is on the rise, and it affects culture so immensely. The Internet and all that it makes available are not intended to be to our detriment. Humans are meant to live above the cons of these evolutions. Families should prioritise what is important to them to make ample time available for spouses and children. It is a fact today that parents are losing out their family bonds to conversations on the phone, and children are getting more and more caught up with games, thereby paying less attention to books. In a case such as it, it is necessary to note that continuous digital evolution is inevitable. This situation implies that culture is now more than ever a dynamic process. However, human persons though being the subject and object of communication should be in charge. Auditing one's communication and social interactivity should indicate where a digital detox, selfdisclosure and emotional intelligence is required.

Having identified the interconnectivity between the concepts of Digital Spatiality, Time, Culture and Human Communication and critically appraising their impact on the family, being the microcosm of society, this paper pointed to emotional connections as being the object and subject of digital spatiality, time, culture and human communication. Considering human communications continues throughout a human person's existence, it is imperative to discuss [because of recommendations] the discretion in self-disclosure and applying emotional intelligence theory for human communicativity in contemporary digital spatiality.

The Self-disclosure concept earlier discussed in this study is a path to balance in human, family and interpersonal despite digital spatiality. It is the act of discretionally revealing details about ourselves to another person or people - the issues in disclosure spans from releasing 'unimportant' details to sensitive and then personal information. Self-disclosure evokes trust and develops human relationships. It is also necessary for uncertainty management and family cohesion.

Other philosophies that emphasise self-disclosure while explaining human communicativity and relationships include Johari window of self, Social Penetration Theory (SPT), communication privacy theory (CPT), and social exchange theory. Disclosure is a critical factor in the development and sustenance of human communication. Self-disclosure enables the permeation of boundaries, benefits of interactivity are well-thoughtout, and information flows freely. Intimacy grows as disclosers' peel off' the 'artificial barriers' to the core persona while connecting as social beings.

Individuals amidst families must embrace 100 per cent self-disclosure through every communication channel possible to make their relationship stronger regardless of where technology takes us in the future. In connecting with persons outside the immediate (nuclear) family, prudence must be employed in determining what to disclose or otherwise.

Our devices matter to us as much as food and shelter; Technology has altered time flow. The overall time that we have for our narrative, our life span, has been increasing, but the smallest measure, the moment, has shrunk. But there's hope still. The world will continue to experience digital evolution. Still, we can communicate better by applying emotional intelligence, self-disclosure with family and exercising self \& social awareness in all forms of digital communication and relationship management.

Even as communication technologies tilt to face-to-face and biometric identities, this paper recommends further research into integrating emotional intelligence components [self-management, self-awareness, self-regulation, internal motivation, empathy and social skills] in developing communication technology.

\section{References}

Aust., L. A. (2003). The concept of online infidelity. Australian Counselling Association, (pp. 3:120-3.).

Banks, J. B., \& McGee, C. A. (1989). Multicultural education. Needham Heights, MA: Allyn \& Bacon.

Benyamin, D. B. (n.d.). Queensland Brain Institute. 
Caruso, D. R. (2008). Emotions and the Ability Model of Emotional Intelligence. In R. J. Emmerling, V. Shanwal, \& M. Mandal, Emotional Intelligence: Theoretical and Cultural Perspectives. Hauppauge, New York: Nova Science Publishers.

Dawaesar, A. (2013). Life in the Digital Now. TEDx Talk.

Evans, D. (2001). Emotion: The Science of Sentiment. Oxford University Press.

Goleman, D. (1995). Emotional Intelligence. New York: Bantam Books.

Griswold, W. (2012). Cultures and Societies in a Changing World. Thousand Oaks, California: Pine Forge Press.

Higginsa, E., \& Seminb, G. (2001). International Encyclopedia of the Social \& Behavioral Sciences. Communication and Social Psychology.

History of Communication from Cave Drawings to the Web. (n.d.).

Holtzapple, A. (2015, February 3rd). Evolution Of Communication: 1800s And 1900s.

Irvin, M. (2018). A Guide for Social Media Digital: How Social Media Affects Marriage. Digital Divorce.

King, S., \& Moreggi, D. (1998). Internet therapy and self-help groups - the pros and cons. Ontario Health Promotion E-Bulletin.

Kotchemidova, C. (2010). Emotion Culture and Cognitive Constructions of Reality. New York.

Kroeber, A., \& Kluckhohn, C. (1952). Culture: A critical review of concepts and definitions. Harvard University Peabody Museum of American Archeology and Ethnology Papers 47.

Livestrong.com. (2013). Internet Addiction and Health Effects.

Lobar, S., Youngblut, J., \& D., B. (2006). Cross-cultural beliefs, ceremonies, and rituals surrounding a loved one's death (pp. 44-50).

M., C., \& M.S., D. (2017). Conn’s Translational Neuroscience. Language Processing, Development and Evolution.

Masaviru, M. (2016). Self-Disclosure: Theories and Model Review. Journal of Culture, Society and Development, 18.

Mesquita, B., \& Albert, D. (2007). The Cultural Regulation of Emotions. (pp. 486-503). Guilford Press.

Ministry of communication and information technology in Saudi Arabia. (2014, 4 12). www.mcit.gov.sa.

MSNBC.com, C. A. (1999). Sexuality on the Internet: From sexual exploration to pathological expression.

N. Gayathri, \& (Dr.) Meenakshi, K. (2013). A Literature Review of Emotional Intelligence. International Journal of Humanities and Social Science Invention, 42-51.

Roy M, B. (2007). Communicating: A Social and Career Focus.

Sally, P., Julie, F., \& Beverley, F. (2006). Cambridge handbook of personal relationships. Emotion in theories of close relationships, 369-384.

Sally, P., Julie, F., \& Fehr, B. (2006). Emotion in Theory of Close Relationship. Cambridge handbook of personal relationships (p. 16). Cambridge, UK: Cambridge University Press.

Valenzuela, S., Halpern, D., \& Katz, J. E. (2014, July). Social network sites, marriage well-being and divorce: Survey and state-level evidence from the United States. Computers in Human Behavior, 36, 94-101.

Young, K. (1999). The evaluation and treatment of internet addiction. In V. C. L, \& J. T, Innovations in clinical practice (pp. 1-13.). Professional Resource Press.

Young, K., Griffin-Shelley, E., Cooper, A., O’Mara, J., \& Buchanan, J. (2000). Online Infidelity: A New Dimension in Couple Relationships with Implications for Evaluation and Treatment. Sexual Addiction \& Compulsivity. 59-74. 